\title{
Does audit result in change in practice? The Lothian surgical experience
}

\author{
S J Nixon
}

Supporters of medical audit presume that doctors can be influenced by discussion of data describing their own clinical performance and comparing these results with similar data from close colleagues. Some would argue that this presumption is not proved and that an "audit of audit" might conclude that audit does not necessarily effect change. Scientific examination of various methods designed to change doctors' practice lead to the conclusion that there are major difficulties to be overcome in making and sustaining changes in practice. The white paper Working for Patients, ${ }^{1}$ which boosted medical audit to its present high profile position, used the Lothian surgical audit to illustrate the successful application of audit principles. It is therefore reasonable to ask what evidence exists that this audit has effected change. Few publications have been directly attributed to Lothian surgical audit ${ }^{2}$ as Lothian surgeons have not chosen to document their work in this way. One reason for this apparent failure is that audit is essentially an exercise in influencing "me" rather than "you." Conclusions may have considerable local impact though being of little national interest. It has also been difficult to persuade journals to accept articles of an audit nature as they have been more attracted to the examination of new concepts in management rather than to study of the application of standard treatments. Audit can be categorised into individual, unit, area, and national audit, depending on the intended sphere of interest. Lothian surgical audit is an example of area audit, and resulting changes in area provision of surgical service are most easily identified from it. Changes in the behaviour of individual clinicians are more difficult to document with certainty. I have attempted to identify some aspects of practice in which I believe that the audit has effected change in local working practices, but I would accept that audit is only one influence in a multifactorial situation, where isolation or weighting of individual components is extremely difficult.

\section{Basic method}

Reduced to its most simple state, Lothian surgical audit is a system whereby individual teams of surgeons in all surgical specialties present an annual report to their colleagues at an open meeting which takes place each Saturday morning between 9 am and $10 \mathrm{am}$. Medical staff collect accurate data on operation workload and mortality in a standard fashion which allows collation of 25000 operations and 400 deaths annually. A unique coding system of diseases and operations, developed by the surgeons, has been widely used for 10 years. Data on deaths are also collected in a standard way, allowing accurate mortality for each disease and each operative procedure to be calculated. Reports often contain additional information regarding outpatient activity and special interests such as vascular laboratory work and anorectal manometry. All surgical units in the Lothian area of Scotland participate, but the concept has spread to non-surgical specialties which have close links with surgery, such as anaesthetics, medical and radiation oncology, and medical gastroenterology. After presentation of basic statistics and discussion of deaths short papers are given which describe areas of special interest, often using historic data in the Lothian surgical audit as a starting point and showing how the service has been developed during the previous year. No limitations are placed on speakers, who are able to compare their own recent performance with historical data from their own unit; retrospective, combined data from Lothian; and literature reviews. Since 1983 the data have been held on microcomputer, improving accuracy, speed of analysis, and accessibility. Responsibility for accuracy of the data belongs to the individual units, who respond by taking considerable care in collecting and presenting data. There is regular, free, and frank discussion from the floor involving both junior and consultant staff. At the end of the year data from all units are combined into an annual report, allowing trends to be identified which may not be apparent from the individual unit reports.

\section{Where audit has made particular impact} Vascular surgery

Developments in vascular surgery best illustrate the value of area audit. During the 1970s ruptured abdominal aortic aneurysm was treated as a general surgical emergency requiring no particular specialist involvement. However, a small number of surgeons were developing interests in vascular surgery. Data collected during this period and presented to the Lothian surgical audit showed a consistent pattern whereby mortality in non-specialist hands was double that of surgeons with an interest in vascular surgery. Put bluntly, an operation performed by a vascular surgeon was likely to result in survival whereas the same operation performed by a non-vascular surgeon most often resulted in a fatal outcome. These data were used to convince surgeons and management of the need for a dedicated vascular unit, which was finally
Hestern General, Edinburgh

EH4 2XU

$S$ J Nixon,

consultant surgeon 
established in 1986 and able to report recent results equal to the best reported in the world literature. ${ }^{3}$ Colleagues in vascular surgery now have the most advanced surgical audit system in Lothian, and it is continuing to develop further. They have taken a particular interest in coding, ${ }^{4}$ realising the weakness of the existing system. They have shown that the acquisition of accurate, basic, audit data promotes the collection of more detailed information and have extended outcomes measures far beyond that of mortality. Successful completion of the audit cycle is a strong catalyst for further audit.

\section{Surgery for peptic ulcer}

Lothian surgical audit has accurately documented major changes in peptic ulcer surgery during the 1970s and ' 80 s, initially the transition from truncal vagotomy and drainage to highly selective vagotomy, followed by the decline in elective surgery in the 1980 s from almost 400 procedures annually to less than 40 (figure). During the same period emergency surgery for perforated peptic ulcer, with a mortality of $10 \%$, has fallen only slightly and surgery for bleeding ulcer has remained constant, as has its mortality of $20 \%$ (figure). Stimulated by these observations and realising the limitations of the data, surgeons have been encouraged to examine Scottish national data, which show the same overall trends but also that, in women, the incidence of complicated peptic ulcer is rising, possibly under the influence of smoking in young women and the use of non-steroidal anti-inflammatory drugs in elderly women. The high mortality of surgery in bleeding peptic ulcer has promoted various policy changes in Lothian, including transfer of initial clinical responsibility from physicians to surgeons, with little effect. Much more effective has been the introduction of areawide provision of expert, emergency sclerotherapy. ${ }^{5}$ This work, initiated by medical colleagues who were aware of the relatively high mortality of emergency surgery and strongly supported by Lothian surgical audit, general surgeons, and physicians, has shown that early endoscopic intervention can reduce the complication of rebleeding to less than $30 \%$ of that previously. Rebleeding is established as a predictor of surgical intervention and is an established mortality risk factor. In a controlled study the need for surgery was halved after injection therapy. Audit may provoke change directly but may

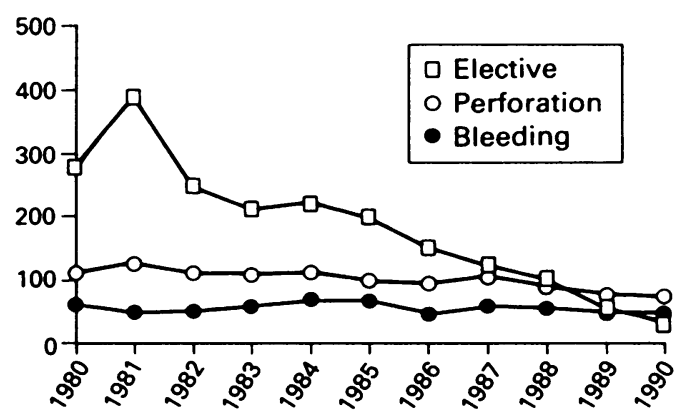

Surgery for peptic ulcer, Lothian surgical audit, 1980-90 also stimulate local research resulting in improvements in patient care.

\section{Breast disease}

An internationally renowned centre from breast disease was established in Edinburgh during the 1970s, coinciding with improvements in the Lothian surgical audit. The audit has accurately documented the changes in management of benign and malignant breast disease, and this unit illustrates how audit and scientific research can coexist and flourish in the same environment. The recent report from the breast unit has highlighted one of the problems of a successful service - that is, the failure of provision to match patient demand. The audit data have been of considerable value to both the breast and the vascular units in discussions with management regarding appropriate staffing of these highly successful units. However, the meeting concerning the breast unit also reminded surgeons that treatment of more common and often minor conditions needs constant re-examination. Data collected in Oxford and Edinburgh show that breast abscess is best treated by needle aspiration and appropriate antibiotics rather than by the more traditional method of surgical drainage. ${ }^{\circ}$ Audit is primarily an exercise in education. It is a catalyst of change not only in high risk areas and novel developments but also, and perhaps more importantly, in the most common conditions. We have consistently shown high recurrence rates after surgery for inguinal hernia and varicose veins, a common problem in the NHS. Audit should not be confined to major surgery nor to mortality but should be applied to minor surgery where deficiencies clearly exist.

\section{Keyhole surgery}

In the past two years surgeons have faced a revolution with the introduction of minimally invasive, keyhole surgery. Three surgical teams in Lothian have already been able to present local data, my own unit showing a reduction in analgesic requirement to $20 \%$ of that previously, in hospital stay by more than six days, and in all measured complications. The only disadvantage has been a deterioration in outpatient waiting times as a result of increased theatre use and rising referrals to a unit unable to meet patient demand. We are presently discussing with management how best to develop this service and the desirability of a multidisciplinary, specialist unit along similar lines to the vascular and breast services.

\section{Conclusions}

Lothian surgical audit has existed since the 1940 s and continues to flourish. It has become a major part of surgical life in the south east of Scotland and has influenced neighbouring regions of Fife, Forth Valley, and the Borders. It has spread out with surgery to associated specialties. As with any institution, the degree of participation in this audit varies, but all surgeons, without exception and without 
compulsion, provide input to it. The audit is clearly not the only influence on surgical practice. Occasionally, its data have been used to effect major changes in organisation of the surgical service. Estimating the influence of this audit on individual practice is more difficult, but it is hard to escape the conclusion that all Lothian surgeons must be influenced by it to some extent. Surgeons are encouraged to re-examine working practice annually, to justify what they have done, and to compare their results with those of their colleagues. The evolution of Lothian surgical audit has been gradual but the recent emphasis given to audit has accelerated development of this audit into areas of staff training, case mix, morbidity, and resource management. The success of the Lothian surgical audit has been based on accurate data, high compliance, and acceptance of peer review. As long as surgeons can see that peer review results in the implementation of change and improvements in practice, Lothian surgical audit is assured of a successful future.

1 Secretaries of State for Health, Wales, Northern Ireland, and Scotland. Working for patients. London: HMSO, 1989. (Cmnd 555.)

2 Gruer R, Gordon DS, Gunn AA, Ruckley CV. Audit of surgical audit. Lancet $1986 ; \mathrm{i}: 23-6$.

3 Jenkins AM, Ruckley CV, Nolan B. Ruptured abdominal aortic aneurysm. Br f Surg 1986;73:395-8.

4 Callam MJ, Haiart D, Murie JA, Ruckley CV, Jenkins AM. Ruptured aortic aneurysm: a proposed classification. $\mathrm{Br}$ I Surg 1991;78:1126-9.

5 Rajgopal CR, Palmer KR. Endoscopic injection sclerosis: effective treatment for bleeding peptic ulcer. Gut efrective treatmen

6 Dixon JM. Outpatient treatment of non-lactational breast abscesses. Br $\mathcal{F}$ Surg 1992;79:56-7. 